\title{
Raising Awareness About Women in Turkish Maritime Industry
}

\author{
Nihan ŞENBURSA ${ }^{1}$, Pınar ÖZDEMİR ${ }^{2}$ \\ ${ }^{1}$ Ordu University, Fatsa Faculty of Marine Sciences, Turkey \\ ${ }^{2}$ Piri Reis University, Maritime Higher Vocational School, Turkey \\ nihan.senbursa@gmail.com; ORCID ID: https://orcid.org/0000-0001-5144-4240 \\ pozdemir@pirireis.edu.tr; ORCID ID: https://orcid.org/0000-0001-9878-8139 \\ Corresponding Author:Nihan SENBURSA
}

\begin{abstract}
The maritime sector is male-dominated. Women working in this sector face the challenges of not only working in a male-dominated working environment but also being at sea, far from their home and families for a long time. Moreover, they struggle with many misperceptions and prejudice against them. In this study, such negative feelings against women in the Turkish maritime sector are examined thoroughly, and the elimination ways of them are examined. The data in this research have collected by employing survey and structured interview methods. After evaluation, the main stakeholders who have a role in building career path of the women in maritime industry are determined as being the women themselves, their male colleagues, families, education institutions, and employers in the sector. In conclusion, the roles of these stakeholders in eliminating negative attitudes towards women are discussed.
\end{abstract}

\section{Keywords}

Maritime, Women, Misperception, Prejudice, Stakeholders.

\section{Introduction}

Research shows that women working in male-dominated sectors have some problems that are different from those of other working women [1]. Maritime is a male-dominated sector where women may face unique problems because they not only work in a male-dominated environment but also live there, and they are far from their families and home for extended periods. Therefore, it is commonly observed that they have some problems particular to this sector; however, these problems have been ignored for a long time. It was only when more maritime schools opened their doors to female students and more women began to be employed in the sector that researchers began to study what their problems are and how they can be solved. The number of female students in maritimerelated departments is still considerably limited. That means female cadets go from male-dominated classrooms to maledominated workplaces. In other words, they start to experience the challenges of male-dominated working environment as

To cite this article: Senbursa, N. \& Ozdemir, P. (2020). Raising Awareness About Women in Turkish Maritime Industry. Journal of ETA Maritime Science, 8(3), 194-209. 
early as they start university education [2]. This situation may cause several problems, and something should be done to help them with their fight against all these potential problems like discrimination, bullying, or harassment. Thus they can actualize themselves and maritime industry can benefit from all they can contribute to the sector.

\section{Literature Review}

\subsection{Global Approaches To Women}

In 1988, the support of the International Maritime Organization's (IMO) strategy for the integration of women into the maritime industry, and the following year, the implementation of IMO Women in Development Program, accelerated the admittance of women to the maritime world [3]. In today's world, similar approaches still are performed by the IMO and international nongovernmental organizations such as United Nations, Global Fund for Women, and The Association for Women's Rights in Development. IMO Secretary-General Kitack Lim emphasizes the importance and urgency of the realization of the UN Sustainable Development Goal (SDG) 5: Gender equality in the shipping industry [4]. Within the scope of SDG 5, IMO keeps its commitment to achieve gender equality not only at sea but also onshore jobs by adopting "Achieve gender equality and empower all women and girls" [5].

Supporting women in the maritime industry and increasing women employment both working onboard as seafarers and onshore in managerial positions as maritime professionals shall only be provided by implementing new approaches to maritime sector dynamics. Encouragement of women can be sustained by discovering two pioneer aspects: 1) by enabling their attainment to the essential education and their participation to the labor force, and 2) by supporting them both at entry-level positions and any stage of their career [6]. Women have advanced analytical and multitasking skills which are demanded by shipping companies [7]. The preference of women employment in the maritime sector shows concrete results. According to the McKinsey Report (2018), the companies in the top-quartile in terms of gender diversity, which executive teams also consist of women were $21 \%$ more likely to outperform on profitability and $27 \%$ more likely to have superior value creation [8]. Therefore, the report's results showed that companies that had great performance on both profitability and diversity had more women in line (for example, income-generating) roles than in staff roles on their executive teams. In the maritime industry, if women are triggered and pulled to the maritime sector as part of a diverse maritime workforce, wider opportunities for women will be suitable both at leadership and managerial positions which is a benefit in a competitive market like maritime [9].

According to the International Labor Organization's Report (2019), share of women in managerial positions by region, between the years 1991-2018 is as following: world's average $27.1 \%$, Americas $39 \%$, Europe and Central Asia $34.4 \%$, Asia and The Pacific $22.5 \%$, Africa $20.3 \%$, Arab States $11.1 \%$ [10]. However, the number of women who are in managerial positions and in chair company boards is still limited. The share of women sitting on company boards, from 2010-2016 varies from $0 \%$ in Germany to $4.6 \%$ in the United States, which showed that glass disparity needs both in the international and national arena [11]. Since maritime women's contribution to the maritime sector has been underestimated, women at managerial positions haven't had a chance to confute. Therefore, raising awareness of the success of women in the maritime industry was not sufficient [12]. 


\subsection{A Global View of Maritime Women in Recent Years}

The obstacles for maritime women are not the same as they were sixty years ago. Thanks to the battle won by the first women seafarers in history, in today's world, maritime women can access to many maritime institutions. As stated in World Economic Forum's Global Gender Gap Report 2020, among Nordic countries, Sweden is holding the highest record, with $15.7 \%$ of female graduates from Science, Technology, Engineering and Mathematics (STEM) programs [13]. In order to create more awareness, it is important to promote and introduce maritime fields and ocean sciences (in the fields of science, technology, engineering, and mathematics (STEM)) to more women and girls in their early ages [14]. In recent years, regardless of their sex, maritime students (especially studying deck and engine departments) have had serious problems with finding internships onboard both in the world and in Turkey. According to the survey held by Ghosh \& Bowles (2013) among Australian Maritime Education and Training (MET) Institutions, the results reconfirmed these struggles on finding suitable cadetship onboard [15]. The struggle starts from their studentship cadet program onboard.

From an industrial perspective, it is an undeniable fact that struggles, problems, and bad experiences that maritime companies encounter in terms of women seafarers and women holding managerial positions have a butterfly effect on the approach of maritime entities [16]. The prejudices of ship owners and maritime companies set a big challenge for young ladies which make them feel discriminated at the beginning of their professional life.

In the transport sector, as well as in the maritime sector, women are considered incapable and weak both physically and mentally. Stereotypes about women in the transport sector may end up with low demand of female community. Therefore; employment and training problems become more difficult for female students and women in Science, Technology, Engineering and Mathematics (STEM) fields [17]. It is a crucial fact that ship owners should be encouraged to giving equal opportunities to accept female cadets onboard considering the importance of this process in having experience in the field. Some maritime companies have already started to support maritime women and give them fair chances to show their skills and abilities . These companies cooperate with maritime education and training (MET) institutions to employ current cadets meaning future officers [18].

\subsection{The Admission of Women to Maritime Colleges}

Until the late 1970s, many women seafarers were facing barriers in acceptance to the maritime institutions, and maritime schools' criteria, mostly aimed at supporting men. However, the acceptance of women to the maritime faculties and maritime education and training institutions dates back to the 1970's in the world [19]. Some examples of women admission dates to the colleges are as following: 1920's in Russia, 1950's in China, 1970's in the USA, Sweden, Portugal, Ghana [19]; 1990's in Turkey [20] and Chile [21]. For the first time in Turkey's history, in the academic year of 1991/1992, Istanbul University, Faculty of Engineering, Department of Maritime Transport Management Engineering started to accept female students (total quota of 26 students). After this, in order to provide academic proficiency of maritime women, in 1997 Dokuz Eylul University, School of Maritime Business and Management, in 1999 Istanbul Technical University Maritime Faculty and Near East University Maritime Faculty, and in 2001 Karadeniz Technical University Surmene Faculty of Marine Sciences followed this approach for women 
seafarers. Henceforth, as trickle-down effect, manymaritime schools in Turkey have opened its doors to female students [20]. Thanks to these successful initiatives, in the process of time, the ambition inside the first women officers made them warriors of the oceans and helped them to become the first women Master Mariners in Turkey. The path to success was not easy. This struggle for existence in their career was to refute against bias [21].

\section{Method}

The aim of this study is to determine the factors preventing awareness of women's contribution to the Turkish maritime sector and to discuss the ways to improve them.

To this end, two methods were used to obtain the data. Firstly, a 11-statement survey aiming to question the awareness for women's contribution to the maritime sector was prepared and given to all the stakeholders, such as both men and women seafarers, employers, ship owners, people working in maritime companies, and maritime entrepreneurs in the sector. The first two statements in the survey were questions while the rest nine statements were propositions. The first question of the survey was a demographic question to learn the gender of the respondents while the others were those prepared to see their perceptions of women in the sector, to learn the problems women face and to study the ways to solve them. The survey was responded by 657 people from the maritime sector. Since the first question, which asked the gender of the respondents, was left blank by some respondents, it was not possible to say how many women and how many men participated in the survey. This is a limitation of the research. However, the gender distribution of the respondents can roughly be estimated taking the percentage of those who responded to the first question into consideration. Among 657 people who joined the survey, 185 people answered the first question. $38,4 \%$ of these respondents were women (71) and $61,6 \%$ of them were men (114). The survey was given in Survey Monkey and the choices were categorized as "Yes", "No" and "Maybe".

The second method used in the research was the structured interview method which was conducted with 48 people, 22 of whom are women. The interviewees were from different positions in the sector. Most of them were seafarers. Some of the rest were employers while some were just company workers at different positions. All male interviewers had some experience of working with women. Each interview took approximately 20 minutes since 11 questions were asked and some detailed responses were expected. Some interviewees gave short answers while some of them gave detailed answers which included their own experiences. We took notes during the interviews, and after all the interviews were finished, we used the data we obtained in the comments and explanation parts of each question. It is also used to support the findings part of this paper. The questions were clear and easy to understand and answer, so the interviewees didn't come up with some issues which may stir ethical concerns. During the interviews, which were face to face, we observed that some of the interviewees were hesitant to clearly express their opinion for fear of offending the interviewers, who are women. This was another limitation that we tried to overcome by assuring them that their names wouldn't be revealed in the study and that this was scientific research which required correct answers. The interviewers were from different positions in the sector. Most of them were seafarers. Some were employers while some were just company workers at different positions. All male interviewers had some experience of working with women. Each interview took about 20 minutes on average since 10 questions were asked and some 
detailed responses were expected. Some interviewees gave short answers while some of them gave detailed answers which included their own experiences. We took notes during the interviews, and after all the interviews were finished, we used the data obtained through the comments and explanation parts of each question. It is also used to support the findings part of this study. The questions were clear easy to understand and answer, so issues, which might stir ethical concerns, were not emerged by interviewees.

\section{Findings}

In the following part, each question in the survey, the number of its respondents, and the percentages of the options chosen are given together with the responses in the structured interview.

1. Do you think that the maritime industry is known enough in Turkey? Do you think necessary and promotional activities for the development of maritime culture in our country are carried out?

$78 \%$ percent of 651 respondents who answered this question gave a negative answer while only $11 \%$ replied positively. $11 \%$ of the respondents had either no idea or did not want to comment on this. That result indicates that many of the respondents think that maritime industry is not well-known sector in Turkey. Interviews made on this subject indicate that the participants think that Turkey has a big potential in the maritime sector, but cannot make use of it much enough and the promotion of the maritime sector is made by the maritime schools only. They also express that the cadets who prefer to go to these schools usually come from the coastal areas. Besides the respondents who say there is a slight increase in the number of people prefer to work in the maritime sector despite very limited promotion activities, there are those who claim maritime culture is getting lost day by day. Moreover, some respondents think the maritime sector is under the control of the wealthy people only. One of the interviewees said, "Only the rich people can take part in sea-going activities. Since it requires a lot of money, the poor people cannot participate in these, even if they want to. It is too expensive." Consequently, it is seen that the vast majority of respondents think the maritime sector is not well-known in Turkey and promotional activities for the development of maritime culture in our country are not carried out.

\section{Is maritime business specific to men?}

$28 \%$ of the respondents gave a positive answer to this question contrary to the $65 \%$ who gave a negative answer. $7 \%$ of them were indecisive. These figures show that maritime is not seen as a men's job. However, the fact that there are a lot more men in the sector than women shows that women don't prefer this job. Statistics show that the percentage of women in the sector is about $1-2 \%$ [22].

The data obtained from interviews prove that there is a negative perception for women in the sector. Although the success of women in the sector is an important factor to eliminate this perception, there are not many good role models since there are not many women in the sector. Those who claim that maritime is specific to men say that technological developments eliminate the differences deriving from gender, but actually, they do not prove useful because they do not change the fact that women are more vulnerable than men, but some interviewees have pointed on something that can be changed. They said "It may be hard at the beginning, but the women who really want to work in this sector will be persistent and she will be able to do most things that she could not do at the beginning because of not being as strong as men. Exercise and hard work will help women to have a strong and enduring body." Another interviewee said "The effects of menstrual 


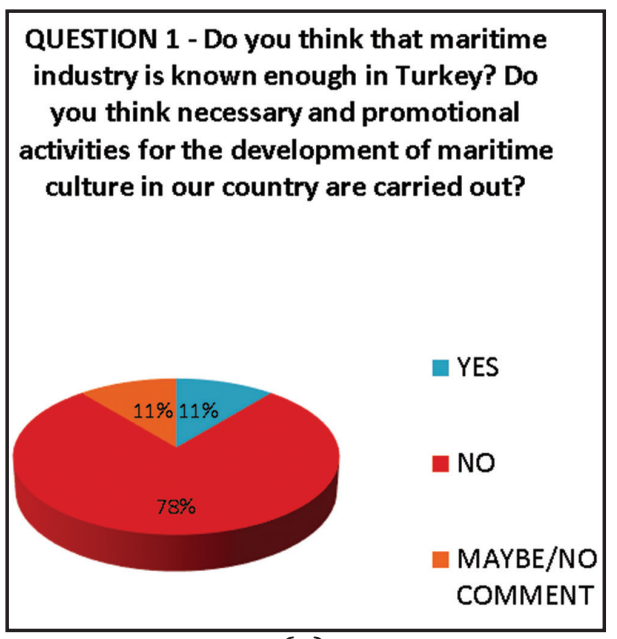

(a)

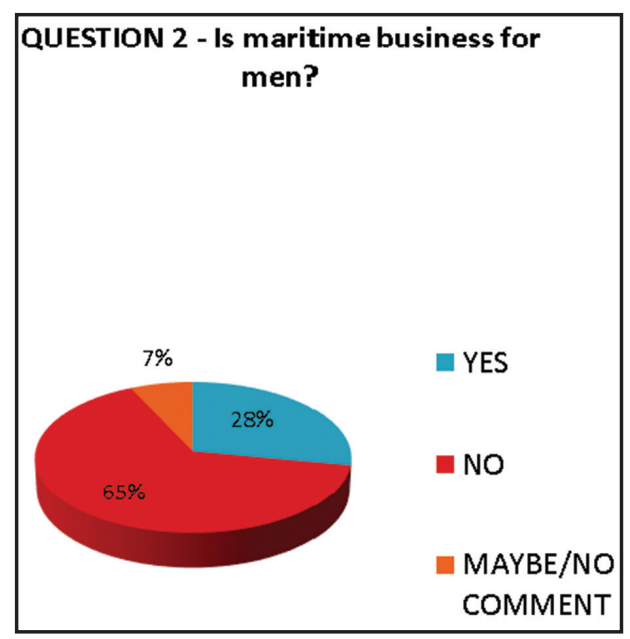

(b)

Figure 1. Percentage of replies for questions 1(a) and $2(b)$

cycle on the physical working capacity of women are clear. Some men use this as an excuse not to employ women onboard. They know this is a temporary situation, but they do not want to accept this." Another one advised, "On-the-job training emphasizing the benefits of women onboard may be helpful for men to accept women as equal colleagues onboard." Despite all these negative perceptions, the statement that the maritime sector is not under the control of men is accepted by a majority as high as $65 \%$, which is a good sign for the existence of women in the sector.

3. Due to the physiological structure of women, that is because of the physical aspects of them, it is difficult to work at sea and onboard for her.

$15 \%$ of the participants have no idea aboutthis topic. Halfof the restagree with the statement above while the other half don't. Maritime, which has long been thought to be more suitable for men [23], has started to get rid of this prejudice by digitalization and technological developments [24]. That the percentages of the respondents who agree and do not agree with this statement are close to each other can be seen as an improvement. On the evaluation of the comments made by the interviewees on this statement, it is seen that the success and efficiency of the women working on board will definitely eliminate the prejudices. One of the interviewees who is a captain said that "I worked with a lot of female onboard and witnessed that they created a positive awareness to a great extent". The statement proves that if people have a chance to work with women they will appreciate their positive contributions to life onboard. On the other hand, there are those who say that prejudice against women is very hard to break down and there are still some jobs that require physical strength despite the improvements on the technical field. The biggest handicaps for women about this are the pregnancy and child-bearing. Women are away from the ship during these periods and cannot go far away from their children because of maternal obligations. For a woman with children waiting for her at home, going back onboard ship and working as enthusiastically as before are very hard, if not impossible.

4. In the maritime profession, which is male-dominated, it is difficult for women to exist both onshore and onboard.

$52 \%$ of the respondents agree with this 
statement while $40 \%$ think the opposite. The maritime sector is hard to work in. Seafarers are far away not only from their families and beloved ones for a long time but also from the land and normal working conditions that a workplace on land can offer to them. Therefore, working at sea is hard for anyone, whether men or women. When interviewees' comments on the statements are taken into consideration, it is seen that there is not a big discrepancy between those who accept that working on the land is as hard as working at sea for women and those who don't accept this. Some of the respondents say that women should work on the land, not at sea. However, most of them think that women face hardness both at sea and on land and they can overcome all the hardness when they are supported in a good way. As one of the interviewees puts it, "It is hard to work onboard, but not too hard for women to overcome". On the other hand, in maritime, like with all the men-dominated jobs, there is a misperception and negative prejudice against women. What should be done is that men should be informed about the positive contributions women can make to the sector and accept the equality of the two genders. Another comment made by the interviewees is that women who choose to work onboard are those who have selfconfidence and who believe that they can succeed as much as men can. Women with these characteristics face no problems in coping with the hardships and they can be role models for the others. It seems that most people have firm ideas on the existence of women in the maritime sector since only $8 \%$ of the respondents expressed they did not have any ideas.

5. In the maritime sector, efforts should be made to ensure that the number of women employed in management companies and onboard ships could be higher than men in maritime companies. Actions requiring affirmative action, such as a certain quota for women and a 10\% increase in salaries, are necessary to increase women's awareness in the maritime sector.

$40 \%$ of the respondents gave a positive answer, and 43\% said "no" while 17\% did not have an idea on this statement. It is seen that the number of those, who think positively about this, are almost the same as those who think negatively. Although it may seem right that women should be given a certain quota because of the hardships they face for employment in the maritime sector, it is more logical to take away the hardships preventing them from achieving the positions they deserve rather than to give them a certain quota. When the comments from the interviewees are reviewed, it is seen that allocating a quota to women and, especially, giving a higher salary to women are reacted very severely not only by men but also by women. Besides those who defend that such discrimination will shadow the struggle of women for equality, some claim that it will get a negative reaction from men. Interviewees say that women who really want to work onboard and who are ready to do this properly are appreciated by their colleagues, but there are those who want to abuse the privileges they may get as there may be in every society. Interviewees also express that even treating women fairly, let alone positively, will lead to positive developments. However, the increase in the salary is one point that gets the worst reaction, and there are even those who claim that such a behavior can be called "labor theft".

6. Maritime departments such as Maritime Business Administration, Maritime Transportation and Management Engineering, Naval Engineering, Marine Engineering, etc. can be introduced with the participation of the Academic Staff of Maritime Faculties in high schools.

The vast majority of the participants, that is $80 \%$ of them, approved the idea that this statement conveys. The number of 
people who did not agree with the statement was as low as $5 \%$ while $15 \%$ of them did not have any ideas. The fact that there are more "YES" answers signals that jobs in the maritime industry should be introduced better to the people. When the comments from the interviewees are taken into consideration, it is seen that the promotion of these jobs should be made realistically. That is why cadet candidates should be informed about these schools by those who have experience at sea, and, because of this, who can reveal the negative sides of the job as much as positive sides. Another thing that is pointed out is that the maritime sector should be promoted to the people when they are young and ready to learn and practice new things. As it was stated by an interviewee "The earlier is the better. Even the children at primary school should learn about maritime". This will help them make an informed choice for their future career.

7. Reasons such as marriage and pregnancy cause women to leave the maritime profession early.

Duties like pregnancy and child care, which women undertake because of their

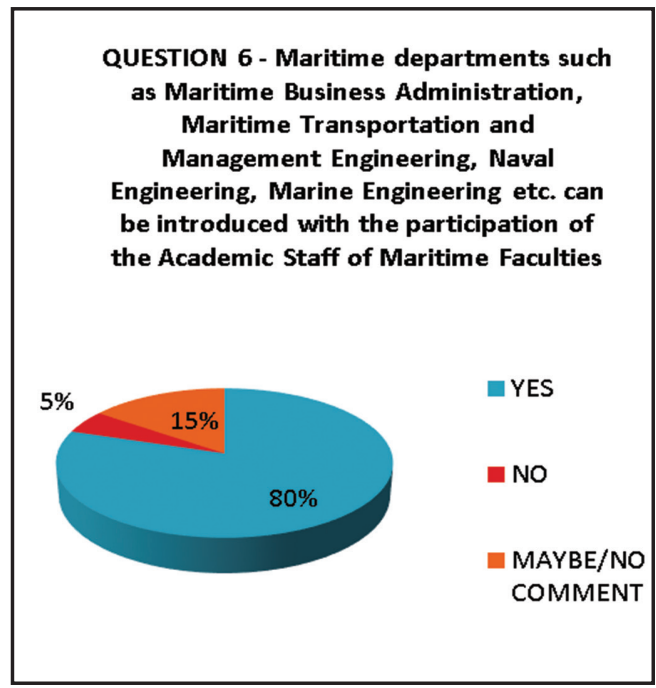

(a) physical structure, cause an interruption in their work-life not only in maritime but also in all sectors. Only $12 \%$ of the respondents do not agree with this idea while $63 \%$ of them think women leave from their jobs because of these maternal duties, as Figure 2 (b) shows. As for the comments from the interviewees, they show that there is a dissidence on this subject. While some of them indicate that this is a natural period that can be experienced with all the jobs, some others say that this subject has something to do with the choices and priorities of women and those who want to go on with their career can do that even when the pregnancy period is over and the children are grown-up enough to start school. One of them says, "Both parents have equal responsibility for children. Male seafarers don't leave their job because they have to look after their children. It should be the same for the female who should go back to their job onboard after the children are grown up enough to be taken care of one of the parents." What's more, they express that sometimes family life and having children can also affect men and cause them to leave their careers as seafarers.

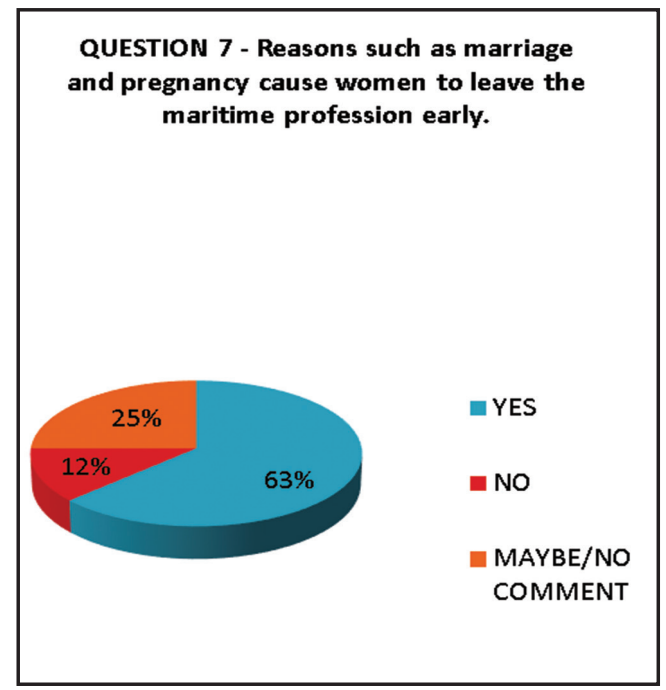

(b)

Figure 2. Percentage of replies for questions 6 (a) and 7 (b) 
8. Women's analytical and organizational skills are better than men.

Responses given to this statement show that the participants have the perception that the dominancy of some characteristics changes by gender, and they think that women have better analytic and organizational abilities. On the other hand, interviewees emphasize that such kind of characteristics do not have anything to do with the gender but with the social and educational background, with the way a person is raised, or with whether or not he has practical intelligence. Despite this, if the facts that the survey was taken by the people in the maritime sector and responses are based on their own experiences and observations are taken into consideration, it can be said that the idea which the statement conveys is correct to a limited degree. Another point signaling this is the discrepancy between positive and negative responses, which are $45 \%$ and $27 \%$ respectively. On the other hand, $28 \%$ of the respondents say that they have no idea. This is a portion which is close to the portion of those who think that women are not better than men regarding those skills. Based on this, it is possible to say that most people in the sector think that women in the maritime sector have better analytical and organizational skills than men.

9. Working in the maritime sector as a ship owner, port, shipyard, broker, freight forwarder is easier for women than working at sea.

A vast majority of the respondents, that is $69 \%$, agree with this idea. $12 \%$ of them do not agree while 19\% express that they do not have an idea. Those with no idea on this statement are more than those who don't think the statement is right. Interviewees believe that working in these fields is easy not only for women but also for men. Some of them comment on the statement by bearing the fact in mind that every job has its own hardships and responsibilities and they express that the field to work in is a matter of preference and because people do what they like easily, working at sea, that is doing the work they like, is not hard for them. One of them says, "It may change from culture to culture, but in our culture, women should be at home early in the evening for a peaceful life at home", emphasizing the fact that cultural values may be effective for the career of women.

10. Negative experiences of women sailors on board (such as accidents, psychological pressure, mobbing, emotional intimacy, extreme emotionality etc.) have a negative effect on ship owners' prejudice regarding female seafarers' employment and the employment of female seafarers on board.

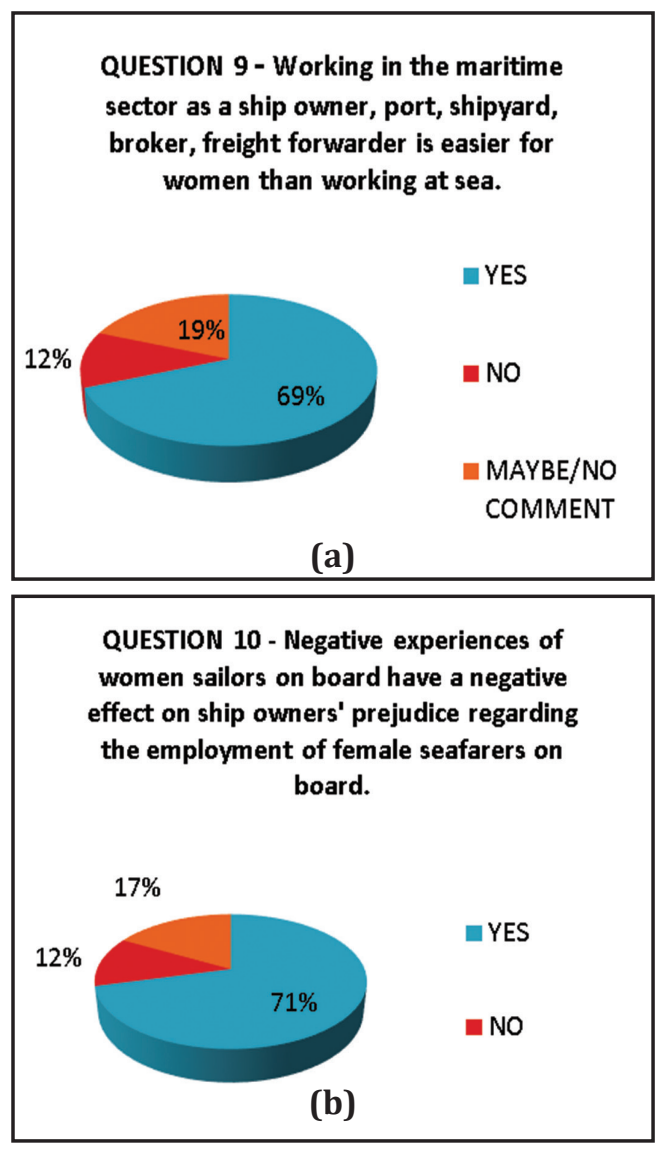

Figure 3. Percentage of replies for questions 9 (a) and $10(b)$ 
As Figure 3 (b) shows, the percentage of the respondents who agreed with this statement is strikingly high (71\%). This signals the fact that women face a great amount of prejudice and there is a long way to go in the maritime sector to break down this. It is seen that not only women but also men agree with the idea this statement conveys and they think such behaviors prevent women from being assigned in maritime jobs. But some comments from the interviewees show that the hardships in question are experienced by not only women but also men and these are valid not only in maritime but also in other jobs. While women claim that people push them around on purpose and men are preferred by the employers especially for seagoing jobs, men claim that is not the case. They say women do not work at sea just because they don't want to and they shouldn't look for someone responsible for this.

\section{Analysis of Findings}

Data obtained from the survey and interviews prove that there is a problem of perception towards women in maritime sector. This paper looks at this problem from the viewpoints of the stakeholders and states what can be done by each of them to eradicate it.

As a result of the research, it is found that although women seafarers like their job and they want to work at sea, prejudice in society and misperceptions of stakeholders about women in the sector prevent them from reaching their goal. To prevent this and to help women in achieving their goal, all the stakeholders, who are the women themselves, the men working with them, families which are the basic building blocks of society, maritime education institutions, and employers in the sector, are expected to do something. By using the data obtained through the survey and the interviews, what the stakeholders are anticipated to do in the process of eliminating misperceptions and prejudice for women are studied and the result is given in the following paragraphs:

Women seafarers are those who choose this job bearing the risks it brings in mind. They are aware of the fact that there is a misperception towards them in the sector and they fight to beat this. They organize meetings, conferences, seminars, and establish networking to strengthen solidarity among them. Since the misperception towards women is commonplace in the sector, IMO decided the theme of World Maritime Day 2019 as "Empowering Women in the Maritime Community" and organized several activities on that day [25]. The activities, which bring all the stakeholders together on this issue, reveal that the prejudice women experience in the sector is the prejudice the women in the maritime sector can face more or less in the same way as in everywhere in the world. It is also understood that these problems stem not only from the misperceptions but also from social and cultural backgrounds and expectations in different countries. Because of these radical reasons, it is not expected that these problems can easily be solved, but there may be some solutions to these such as mentoring and networking, the effects of which can be realized in the long run. On the other hand, despite the hardships women experience in the sector, they refuse to be given some privileges and state that all they want is fair treatment. The only exception to this is the maternity period. In case women want to go back to serve on board after some divine roles and responsibilities they are given by nature such as motherhood or childcare, it will be helpful to give them some privileges such as being assigned at ashore units till the children grow up to a certain age or being given some help for child care. This will be beneficial for both increasing the number of women in the sector and satisfying the need for efficient personnel that the sector needs. 
On the other hand, some interviewees believe that women should end their duty onboard and work at ashore units for good family life.

Men should do their share to help women with their fight against the misperceptions and bias they face in the sector and judge them with the moral and intellectual values which they obtained by working together with women not with those which belong to other people. What is expected from men is not to generalize some bad examples that can be found at every society to all the women in maritime and appreciate those women who do their work well. Women are more emotional and vulnerable by nature compared with men. Men should not take these traits as weakness and instead of going for jugular only because women want to work at a men-dominated sector, which is traditionally their own field, in their opinion, they should try to make use of their strength.

Families which are the basic units of social life are among the important stakeholders who have a role to give the place women deserve in maritime. The character of the people is shaped when they are young. If the families pass down negative feelings and prejudice about women to their children, to the boys, this will influence them during their life. That is why the families must plant the idea of gender equality into their children's minds and support their daughters as well as their sons if they want to go to maritime schools and work onboard ships. It should not be forgotten that education starts in the family.

Maritime schools can take important steps to promote both the sector and schools correctly and to make the human capital stronger in the sector. Those who are interested in sea are people with ties with the sea and those who make use of sea both to make their living and as a hobby. Unfortunately, although our country is surrounded by sea on three sides, only the people living at the seaside are familiar with sea and that's why only the children who have grown up at the seaside want to be seafarers. Therefore, if the promotion of maritime schools is made in a way to reach the remotest parts of the country, more people will be aware of maritime as a job field, and more students, that is more female students, will know about it. An important point here is that those who promote the maritime sector should introduce not only the good sides of it to make more people interested in it, but they should also include the hard sides of it not to make these people disappointed later. That is how people who do not know much about hardships in maritime can be prevented to attend maritime schools and to be a burden on the school's first and then on the sector since they may, sooner or later, realize the fact that they are not suitable to work onboard, so they will want to work onshore or neglect their duties because they don't like them.

Employers are also among the stakeholders who can take some steps to help women for a better career in the maritime. Interventions such as applying a quota for women and making it possible for women to be represented with a certain fraction in the sector are among the ones implied in the survey, but the responses given to the statements about these and the interviews made in the frame of the study show that such interventions are found damaging by both men and women. They indicated that instead of such affirmative actions, there shouldn't be any interventions, neither for men nor for women, which means the negative one should also be erased. When this is possible, the vacant positions will be given to those who deserve them, and women will not be denied some jobs just because they are women. Providing such equality will be profitable for both women and employers, that is, women will find a job to work for 
while employers will have the chance to make use of their skills and abilities. Another thing expressed by interviewees is that employers should do something to eliminate the glass ceiling barrier for women. If there are enough support for pregnancy and early child care periods for women, they will not be prevented from climbing the career ladder in the maritime.

The last thing the interviewees have emphasized is that all these stakeholders should support each other and they need to be in cooperation continuously and closely with each other to eliminate the barriers for women in the maritime sector (Figure 4). Today, technological developments made it easy not only for women but also for men to work onboard. Regarding this, cooperation for the prevention of misperceptions and prejudice against women should be made and more women should be supported to work onboard. This will be beneficial for women to actualize themselves and will have positive effects on the sector, the economy, and the welfare of the country, which will make use of their skills and abilities.

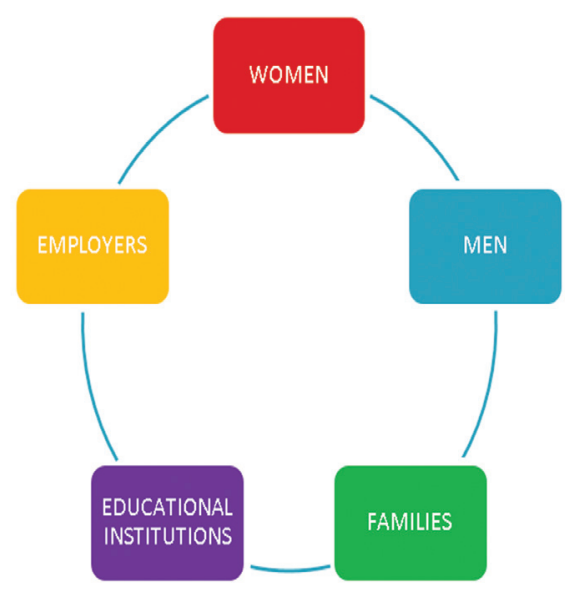

Figure 4. Stakeholders to have a role to eliminate prejudice and misperceptions about women in maritime
As is seen in Figure 4, stakeholders who have the most important roles in changing the misperception and prejudice about women in the maritime sector are women themselves, men who work with women, the families of the stakeholders in the maritime sector, educational institutions where maritime sector employees are trained and educated, and employers in the sector. The sustaining the women employment in the sector, their happiness, job satisfaction, and productivity heavily depend on their relations with these stakeholders as well as the relations among themselves. It is also very important that all these, except for women themselves, should have positive thoughts about women in the sector free of prejudice and misperceptions.

\section{Discussion and Conclusion}

Since the maritime is a male-dominated and demanding sector, it is not easy for a well-educated, qualified woman who wants to work in this sector to find a job as she likes. Even if she finds one, she may have to leave it early because of some negative attitudes towards her. Maritime women, who are well aware of this, have been struggling to cope with the hardships, bias, and misperceptions they face $[1,26,27]$.

There have been many studies and activities to support the struggle of women in getting the place they deserve in the maritime sector. For example, achieving gender equality and empowering all women and girls have been the goals of IMO's Gender Program [5] and employment of women in the maritime sector is supported in the International Women's Conference, 2019 [14]. In addition, the participation of women in maritime jobs is encouraged by various organizations such as IMO. As Tansey [3] points out, they were first accepted to maritime schools over 30 years ago. Since then many conferences, seminars and meetings have been conducted to increase the awareness of people about 
the women in maritime. Unfortunately, none of them have resulted in a significant rise in the awareness for the existence of women in the maritime sector, as Kitada [12] indicates. Their chance to be employed is little in this sector, and to be promoted to the managerial positions, similar to many other sectors, is next to nothing as indicated in the report by International Labour Organization (ILO) [10].

Theoretically, they are given a number of rights, so they are supposed to face less and less obstacles each passing year, but, in practice, as Ghosh \& Bowles [15] and Kitada \& Harada [17] point out they still have difficulty in finding internships as students and finding jobs as seafarers. Although gender equality which is stated in has been made a SDG by IMO, the progress is slow and it seems that it will take decades for women to attain the place they deserve in the maritime sector. Eliminating the barriers is not easy for women, because it is seen that there are a lot of misperceptions and prejudice against women which stem from the social and cultural structure of the society. Instead of accepting women as they are, the belief that women cannot succeed in maritime jobs and the belittlement of their skills and abilities cause irreparable harm to the women as well as to the sector. women state that they want to be accepted as they are, that they don't expect positive discrimination in the employment process but want to be treated equally. Men are expected to treat women the same as they treat other men. They should neither bully women to cause them to leave their job nor protect them just because they are women. The elimination of prejudice that has been created by all kinds of events throughout centuries and coping with the devastating effects of the misperceptions caused by them are not easy, but the struggle to give the women the place they deserve should start from somewhere and all stakeholders should do what is expected from them during this struggle. It should not be forgotten that the most important actors in raising the awareness women's equality in society are families and education and training institutions. For this reason, equal treatment for women and men is not limiting the job choices of women, and not keeping them away from any opportunities just because they are girls should start in the family. Maritime schools should do their share and emphasize that maritime, which is traditionally known as the realm of men, offers career choices for women, too, and women have a voice in maritime, too. Last but not least, employers in the sector should be fair in the employment process and should not refuse candidates only because they are women or hire candidates only because they are men.

As is seen, maritime women have both a glass ceiling above them and glass bulkheads around them which are made of misperceptions and prejudice. These glass bulkheads together with the glass ceiling cause women in the maritime to have a harder career path and a harder self-actualization process in comparison with their colleagues in other sectors. To clear the way women will take in maritime is not so simple as to be achieved by a few stakeholders in a short time, on the contrary, it is a demanding long-term process that requires cooperation by all stakeholders. If all the stakeholders in the maritime sector do their share properly, the maritime will be a preferable and peaceful sector for women. Opening doors to maritime to women, being fair to both genders, supporting women to reach the places they deserve in maritime and making use of the skills and abilities women can bring to the sector will both boost the efficiency and morale of the people, improve internal communication and productivity, and make both men and women committed to their job, which will all benefit the maritime sector. These may be the steps to be taken to give the women 
a space they deserve in the sector. uture research may be about what can be done to realize these, that is, which measures can be taken in the short and long run to help women advance in their career, work productively and make most of themselves in the maritime sector.

\section{References}

[1] Martin, P., \& Barnard, A. (2013). The Experience of Women in Male-Dominated Occupations: A Constructivist Grounded Theory Inquiry. SA Journal of Industrial Psychology, 39(2), 01-12. http:// dx.doi.org/ 10.4102 / s a jip. v39i2.1099.

[2] Ozdemir, P., \& Albayrak, T. (2017). Enhancing Quality in Higher Education Through International Collaboration: Project MENTORESS. In Muzaffer Yilmaz (Ed.), ICQH 2017 International Conference on Quality in Higher Education (pp. 130-136). Sakarya: Sakarya University.

[3] Tansey, P. (2000). IMO. Women on board. - Ten years of the International Maritime Organization (IMO) Women in Development Programme. Recourse document. Retrieved February 2019, from http://www.imo. org/blast/mainframe.asp?topic_ id $=406 \&$ doc_id $=1082$

[4] Lim, K. (2019). IMO. World Maritime Day, 2019. Retrieved November 22, 2019, from http:// www.imo.org/en/About/Events / WorldMaritimeDay/Documents / S G \% 20 m e s s a g e 20 for $\% 20$ website.pdf

[5] IMO, (2019). Women in Maritime, IMO's Gender Programme. Retrieved January 02, 2020, from http://www.imo.org/en/ OurWork/TechnicalCooperation/ Pages/WomenInMaritime.aspx
[6] Tansey, P. (2015). Women at the Helm: 25 Years of IMO's Gender Programme. In Kitada, M. , Williams, E. \& Froholdt L.L. (Eds.), Maritime Women: Global Leadership (1st Edition, pp. 17-22). Heidelberg: Springer.

[7] Stevenson, C. J. (2015). Sustainable Development Issues in Shipping: Women, the Under-Represented Human Resource. In M. Kitada., E. Williams., \& L. Loloma (Eds.), Maritime Women: Global Leadership (pp. 255-265). Berlin: Springer.

[8] Mc Kinsey \& Company (2018). Delivering through Diversity Report.

[9] Pastra, S.A., Koufopoulos, D.N., \& Gkliatis P.I. (2015). Board Characteristics and the Presence of Women on the Board of Directors: The Case of the Greek Shipping Sector. In Kitada, M., Williams, E. \& Froholdt L.L. (Eds.), Maritime Women: Global Leadership (1st Edition, pp. 17-22). Heidelberg: Springer

[10] International Labor Office (2019). ILO. A Quantum Leap for Gender Equality. Gender, Equality and Diversity \& ILOAIDS Conditions of Work and Equality Department. Retrieved April 7, 2020, from https://www.ilo.org/wcmsp5/ groups /public/---dgreports /--dcom m/---publ/d ocuments / publication/wcms_674595.pdf

[11] ILO, (2019). A quantum leap for gender equality : for a better future of work for all. Geneva.

[12] Kitada, M., \& BhirugnathBhookhun, (2019). M. Beyond business as usual: the role of women professionals in maritime clusters. WMU Journal of Maritime Affairs, 18(4), 639-653. https:// doi.org/10.1007/s1343 7-01900178-8. 
[13] World Economic Forum, (2020). The Global Gender Gap Report 2020. Geneva. Retrieved March 22, 2020, from https:// www.weforum.org/reports/gendergap-2020-report-100-years-payequality

[14] World Maritime University, (2019). Conclusions of the Third WMU International Women's Conference: "Empowering Women in the Maritime Community" (EWMC 2019). Malmö. http://dx.doi.org/10.2167 / cr.20190828.

[15] Ghosh, S., \& Bowles, M. (2013). Management of Berths atSea for Seafarer Students.AustralianJournal of Maritime \& OceanAffairs, 5(1),11-21,http://doi.org/ 10.1080/18366503.2013.10815726.

[16] Senbursa, N. (2020). A Review of Maritime Women in The Global Arena. Journal of Maritime Transport and Logistics, 1 (1), 20-25.

[17] Kitada, M., \& Harada, J. (2019). Progress or regress on gender equality: The case study of selected transport STEM careers and their vocational education and training in Japan. Transportation Research Interdisciplinary Perspectives, 1,100009 .

[18] Doumbia-Henry, C. (2019) Foreword for JOMA - Empowering Women in the Maritime Community: The Way Ahead. WMU Journal of Maritime Affairs, 18(4), 521-524. https://doi.org/10.1007/ s13437-019-00187-7.

[19] Kitada, M. (2010). Women Seafarers and Their Identities (PhD Thesis). Cardiff University.

[20] Nas, S. (2014). Profesyonel Türk Kadın Denizcilerinin Kısa Tarihsel Süreci Üzerine Bir Araștırma. Beykoz Akademi Dergisi, 2(1), 29-53.

[21] Başak A.A. (2015). Women's Role in the Turkish and Global Maritime Industry. In Kitada M., Williams E., Froholdt L. (Eds.), Maritime Women: Global Leadership (pp. 103-111). Berlin: Springer.
[22] UNTAC (2017). Review of Maritime Transportation. Retrieved November 19, 2019, from https://unctad.org/ en/PublicationsLibrary/rmt2017. en.pdf)

[23] Raunek, K. (2019) Life at Sea. The Brave Journey of Women Seafarers, Retrieved November 14, 2019, from https://www.marineinsight.com/ life-at-sea/the-brave-journey-ofwomen-seafarers/ )

[24] Demirel, E., \& Ozdemir, P. (2019) Women Studies. In Prof. Dr. Aykut Işman, Assoc. Prof. Dr. Nesrin Akıncı Cotok (Eds.), Women in Digital Age (pp.236-245). Istanbul ISSN 26871777

[25] IMO (2018) World Maritime Day Theme 2019: "Empowering Women in the Maritime Community" Retrieved January, 02. 2020, from http:// www.imo.org/en/MediaCentre/ Press Briefings / Pages / 13 WMD2019themeC120.aspx

[26] Ozdemir, P. Albayrak, T. (2018). Barriers to Women's Leadership in Maritime and the Ways to Overcome Them. In Ed. M. Grifoll, F.X. Martinez de Oses, M. Catells, A. Martin. 19th Annual General Assembly (AGA) of the International Association of Maritime Universities (IAMU). (1st Edition, pp. 305-313) ISBN:978-84-947311-7-4 International Center for Numerical Methods in Engineering (CIMNE), Barcelona

[27] Dragomir, C. Senbursa, N. (2019). Maritime Fair Transport. "Ovidius" University Annals, Economic Sciences Series, 19 (2), 272-277. 


\section{Appendix: SURVEY}

\section{Awareness of Maritime Women in Turkish Maritime Industry}

1. Your Gender Woman ( ) Man ( )

2. Do you think that maritime industry is known enough in Turkey? Do you think necessary and promotional activities for the development of maritime culture in our country are carried out?

Yes ( ) No ( ) Maybe ( )

3. Is maritime business for men?

Yes ( ) No ( ) Maybe ( )

4. Due to the physiological structure of a woman it is difficult to work at sea and on board for her.
Yes ( )
No ( )
Maybe ( )

5. The maritime profession, which is a male-dominated profession, is difficult for women to exist both on shore and and on board.
Yes ( )
No ( )
Maybe ( )

6. Maritime departments such as Maritime Business Administration, Maritime Transportation and Management Engineering, Naval Engineering, Marine Engineering etc. can be introduced with the participation of the Academic Staff of Maritime Faculties in high schools.

Yes ( ) No ( ) Maybe ( )

7. In the maritime sector, efforts should be made to ensure that the number of women employed in management companies and on board could be higher than men in maritime companies. Actions requiring positive discrimination, such as a certain quota for women and $10 \%$ increase in salaries, are necessary to increase women's awareness in the Maritime sector.
Yes ( )
No ( )
Maybe ( )

8. Reasons such as marriage and pregnancy cause women to leave the maritime profession early.

Yes ( ) No ( ) Maybe ( )

9. Women's analytical and organizational skills are better than men.
Yes ( )
No ( )
Maybe ( )

10. Working in the maritime sector as a shipowner, port, shipyard, broker, freight forwarder is easier for women than working at sea.
Yes ( )
No ( )
Maybe ( )

11. Negative experiences of women sailors on board (such as sea accidents, psychological pressure, mobbing, emotional intimacy, extreme emotionality etc.) have a negative effect on shipowners 'prejudice regarding female seafarers' employment and the employment of female seafarers on board.
Yes ( )
No ( )
Maybe ( ) 